Mavi Atlas, 6(1)/2018: 48-66. Araştırma Makalesi | Research Article

Makale Geliş | Received: 15.02.2018

Makale Kabul | Accepted: 20.03.2018

DOI: $10.18795 /$ gumusmaviatlas.418504

Neşe HARBALİOĞLU

Dr. Öğr. Üyesi

Nevşehir Hacı Bektaş Veli Üni., Fen-Edebiyat Fak., Çağdaş Türk Lehçeleri ve Edebiyatları Böl., Nevşehir-Türkiye Nevşehir Hacı Bektaş Veli Uni., Fac. of Sc. and Let., Contemporary Turkish Dialects and Literature Dep., Nevşehir-Turkey ORCID: 0000-0003-0807-4592 nese80nese@gmail.com

\title{
Uygur Atasözlerinde Ölüm ile İlgili Sözcükler Üzerine
}

$\ddot{\mathbf{O} z}$

Kültürel aktarımın gerçekleşmesinde, bilgi ve deneyimlerin paylaşılmasında önemli bir yeri olan atasözleri, deneyimlere ve gözlemlere dayalı düşüncelerden doğmuştur. Toplumsal yaşantı içinde önemli bir yer edinen tüm varlıklar ve olaylar, atasözlerinde kendine bir yer bulur. Bu bağlamda ölüm de Uygur atasözlerinde kendine yer bulmuştur. Ölüm ile ilgili sözcükleri ölen kişi için kullanılan sözcükler, ölüm ile ilgili eylemler, ölüm zamanı ile ilgili sözcükler, ölünün gömülmesi ile ilgili sözcükler ve ölüm sonrası hayat ile ilgili sözcükler şeklinde sınıflandırmak mümkündür. Uygur atasözlerinde ölüm ile ilgili pek çok sözcük kullanılmaktadır. Ölüm ile ilgili sözcükler, ölümün Uygur toplumunun gözlemlerinde ne kadar yer edindiğini göstermekle kalmaz, aynı zamanda onların ölüm ile ilgili dünya görüşünü de yansıtır.

Anahtar Kelimeler: Uygurlar, Yeni Uygur Türkçesi, Atasözü, Ölüm.

\section{On Words Related to Death in Uighur Proverbs}

\begin{abstract}
The proverbs, which have an important place in the realization of cultural transfer and sharing knowledge and experiences, were born of thoughts based on experiences and observations. All beings and events that have an important place in social life, find a place in proverbs. Death in this context also found its place in Uighur proverbs. Death-related words can be categorized as words used for the deceased person, verbs related to death, words related to death time, words related to the burying of dead, and words related to life after death. Many words related to death are used in Uighur proverbs. Death-related words do not only indicate how much the death took place in the observations of the Uyghur community, but also reflect their worldview of death.
\end{abstract}

Keywords: Uighurs, New Uighur Turkish, Proverb, Death. 


\section{Giriş}

Dil, bir ulusun bireylerinin anlaşmasında, o ulusu ulus yapan özelliklerin oluşmasında önemli görevler üstlenen, yapıcı ve yaratıcı bir varlıktır (Dilçin 1983: 22). Bir ulusun kendi tarihi ile paralel yürüdüğü ve sürekli geliştiği sosyolojik karakterli ve ulusal mensubiyetinin temel taşı kabul edilen canlı kültürel anıtıdır (Altaylı 2010: 125).

Canlı bir varlık olması nedeniyle dil, tarihî süreç içerisinde türlü etkenlerle birtakım değişmeler ve gelişmeler gösterir. Bir dilin, doğal olarak ses, anlam, yapı ve sözdizimi açısından uğradığı değişmeler, kuralları ve koşulları sınırlı bir evrimle olur (Dilçin 1983: 22; Özkırımlı 1994: 17, 18). Her dilin kendine özgü kuralları vardır ve bu kuralları çerçevesinde zaman içinde değişir ve gelişir (Özkırımlı 1994: 17, 18). Dillerin kural sistemleri, zaman içinde var oluşları ve form çokluğu ile açık bir şekilde şahsi ruhun alanı dışına uzanır. Onlar kültüre aittir (Wein 1959: 42).

Dil, insanın oluşturduğu bir dünyadır ve bu dünya, insan ile evren arasında bulunur. İnsanın başkaları ile anlaşmasının yarar ve zorunluluğu, insanın biyolojik varlığının temel ihtiyaç ve isteklerinde temellenir (Wein 1959: 42). İnsan için gerçekte öteki insana ulaşmanın, ona bildiri aktarmanın ve ondan bildiri almanın aracıdır (Benveniste 1995: 164). Dil, insanın kültür varlığının temel taşıdır (Wein 1959: 42).

Bir dilin sözvarlığı içinde yer alan atasözleri bir toplumun bilgeliğini, dünya görüşünü, deneyimlerini ve anlatım gücünü yansıtan, yüzyıllarca yaşayabilen sözlerdir (Aksan 2004: 33; Doğan 2009: 87). Nesilden nesile aktarılarak günümüze kadar ulaşan atasözleri, daha önceki kuşakların yargılarını ve gözlemlerini genellikle dilsel bir imge şeklinde, yol gösterici birer kural olarak sunarlar (Sağlam 2001: 46).

Atasözleri, toplumsal yaşantı içindeki bireylerin uymaları beklenen bir genel kural ya da bir düstur niteliğindedir. Bu nedenle de atasözleri, milletlerin karakterlerini, hayat karşısındaki tutumlarını ifade eder (Çobanoğlu 2004: 1). Geniş halk yığınlarının yüzyıllar boyunca yaşadıkları deneyimlerden ve bunlara dayanan düşüncelerden doğmuştur (Aksoy 1988: 132). Uluslar, zengin yaşama deneyiminden çıkardığı dersleri 
atasözü durumuna getirmiş, böylece insanları bilgilendirmek, uyarmak, eleştirmek istemiştir (Çotuksöken 2004: 10).

Atasözleri herhangi bir fikri ya da hükmü tasdik etmek ya da tenkit etmek için "muhakeme edilmeksizin" meşruiyeti sosyal ve kültürel değerlerce onaylanmış en uygun araçtır. Bu işlevin yerine getirilişi ve atasözlerinin kullanımının işleyişi benzer olaylardan ikincisini, birincisinin akla ve mantığa dayanan sonuçları nedeniyle ikinci ya da herhangi bir konuşma durumunda bağlama bağlı olarak doğruluğunun meşruiyetinin temelini oluşturmaya dayanır (Çobanoğlu 2004: 7).

İnsanoğlunun deneyimlerinden, bilgeliğinden ve benzetme gücünden kaynaklanan atasözleri dünyanın her dilinde vardır (Aksan 1995: 362). Atasözlerinde insanoğlunun belli durumlarda belli yargılara varması, kimi gerçekleri belirleyerek özdeyiş biçiminde kesinleştirmek istemesi ve eş ya da yakın benzetmelere gitmesi sonucunda dilden dile benzerlik ve eşlikler doğmuştur (Aksan 1995: 363). Geniş bir coğrafyaya yayılmış olan Türk boylarının atasözlerinde de önemli benzerlikler kendini gösterir. Birçok atasözü, bazen bir iki sözcük değişmesi, bazen de bir iki ses değişmesi ile öteki Türk lehçelerinde görülmektedir (Alkaya 2001: 58). Atasözlerinin aynı dilin değişik lehçelerinde yaşamını sürdürmesi, onların değişik lehçeleri ile aynı dilin öz malı olduğunu göstermektedir (Aksan 2004: 33).

Türkçede eskiden sav, mesel, tabir diye anılmış olan atasözü, Dîvânu Lugâti'tTürk’te Arapça mesel, Türkçe sav; Divan edebiyatında ve Osmanlıcada mesel, darbımesel sözcükleri ile karşılanmıştır (Aksoy 1993: 13, 14). Yeni Uygur Türkçesinde atasözü için maqal-temsil terimi kullanılır. Maqal deneyimler neticesinde halk tarafından yaratılıp, geniş kitlelere yayılan, betimleyici, eğitici nitelikleri bulunan, kalıplaşmış hikmetli sözlerdir (Seper ve Yolboldi 2002: 127; Yakub ve Ğeyurani 1999: 1009). Temsil yaşamdaki çeşitli olayların, kişilerin iyi ya da kötü özelliklerinin hayvan ya da nesnelerin biçimleri, özellikleri ya da durumları üzerinden anlatıldığı hikmetli sözlerdir (Sadık 1995: 485; Rehim 1979: 7; Karaman 2016: 95, 96; Yakub ve Ğeyurani 1999: 291, 292). Temsil de maqal gibi hayat tecrübelerinin bir ürünüdür. Yaşamdaki çeşitli olaylar, insanların iyi ve kötü özellikleri temsilin içine gizlenerek örtülü biçimde 
anlatılır (Sadık 1995: 485, 486). Bügünki işni etige qoyma. "Bugünkü işini yarına bırakma." (LD 132), Dadañ̆ga qilsañ, balañdin tartisen. "Babana ne yaparsan, çocuğundan onu görürsün.” (LD 165) maqal; Böre balisi tülke bolmas. "Kurt yavrusu tilki olmaz." (LD 125), Kuruq tağar öre turmas. "Boş çuval ayakta durmaz." (HEH 486) temsil örnekleridir.

Çağdaş Uygur edebiyatında atasözleri, kendine özgü yapıları ve yol gösterici olma özellikleri ile yaygın biçimde kullanılan önemli bir türdür. Atasözleri çağdaş Uygur edebiyatında ulusun tarihini, sosyal hayatını, maddi ve manevi deneyimlerini aktaran kısa ve özlü sözler olarak ele alınır (Emet 2001: 1; Rehim 1979: 1; Mehmut 2006: 49; Kurban 2008: 49; İbrahim 2004: 35).

\section{Ölüm Sözcüğü}

Kendilerini kullananların zihinlerindeki ifadelerin yerini tutan sözcükler, düşüncelerimizin birer işaretidirler (Ergat 2008: 97). Herhangi bir kültürde bir kavramı ifade etmek için kullanılan sözcüklerin niceliği ve çeşitliliği, anılan kavramların o toplumdaki değerini ve önemini belirleyici bir unsurdur (Güner Dilek 2007: 178). Uygur atasözlerinde ölüm ile ilgili pek çok sözcük kullanılmıştır. Bu sözcüklerin çokça kullanılması onların ölüme ve ölene çok fazla değer vermesinin tezahürüdür. Uygurların bu tutumunun arka planında onların kendilerine özgü ruh anlayışı ve ruh tasavvuru bulunmaktadır. Ata kültü merkezli inanç sisteminden kaynaklanan bu ruh anlayışı, farklı kültür ve dinlerin etkisi ile değişik şekillerde tezahür etse de özde fazla değişmiş değildir (Öger ve İnayet 2013: 51). Ölüm, insan belleğinde doğa karşısındaki güçsüzlük duygusunu tetikleyerek ruhun varlığı ve ölüm sonrası hayat inançlarını ortaya çıkarırken bu hayat teleolojik zeminde iyi ve kötülerin ayrışmasında son derece işlevsel bir rol üstlenir (Öger 2013: 97).

Kültürün vazgeçilmez ifade aracı olan dil, edebî ürünlere toplumun zihin yapısını yansıtmıştır. Bu zihin yapısının oluşmasında olayların algılanış biçimi etkili olmuş ve bu durum atasözlerine de yansımıştır (Duman 2012: 98). Ölüm, inançlarla ilişkili bir 
konu olduğu için o toplumun inanç sistemini de ortaya koymaktadır (Biray 2013: 354). Dilde ahiret, ecel, cennet, cehennem, defin, Azrail gibi sözcüklerin kullanımı bu durumun kanıtıdır (Ersoy 2014: 88).

Her toplum, kendi dilindeki acılı, ayıplı sözcükleri örtme, uluorta söylememe eğilimindedir. Duygu taşkınlıkları kalıplaşmış sözlerin, atasözlerinin, deyimlerin, ağıtların, taziyetnamelerin içinde kendine yer bulur. Ölümün soğuk yüzü karşısında insanoğlu, ölümün adını anmama, örtmece sözler ve şifreler kullanma, başka dillerden alıntı sözcüklerle karşılama gibi çeşitli yöntemler kullanmıştır (Ergun 2013: 134; Tosun 2017: 172). Ölümü gerçek anlamıyla anlatan sözcükler kullanılsa da daha çok dolaylı anlatımlı sözcük, sözcük grubu ve deyimler tercih edilmektedir. Söz varlığındaki bu dolaylı kullanımlar çok ve çeşitlidir (Biray 2013: 354).

Ölüm sözcüğü, Uygur atasözlerinde kendine fazlaca yer bulmuştur.

Ă̆riqni yoşursañ, ölüm aşqara. "Hastalığı gizlesen de ölüm kaçınılmaz." (MR 65); Băg igisi bolsañ üzgin gülüñdin, aşiq bolsañ qorqma ölümdin. "Bahçe sahibi olsan kopar çiçeğinden, âşı olsan korkma ölümden.” (LD 83); Bir ölümge arğa yoq. "Bir ölüme çare yok." (KÖ 137); Düşminiñge ölüm tiligiçe, özeñge ömür tile. "Düşmanına ölüm dileyeceğine, kendine ömür dile.” (KÖ 165); Elçige ölüm yoq. "Elçiye ölüm yok. (Elçiye zeval olmaz.)” (LD 202); Haqaretlik ömürdin, sadaqetlik ölüm yaxşi. "Utandırıcı bir hayattan, şanlı şöhretli bir ölüm daha iyidir." (KÖ 189, 190); Muhebbet ölümni yéñer. "Sevgi ölümü yener.” (LD 431); Ölüm yaş-qériğa baqmas. “Ölüm gence yaşl1ya bakmaz.” (KÖ 256); Ölümdin qutquzarmu til, ölümge tutquzarmu til. "Ölümden kurtaran da dildir, ölüme götüren de." (KÖ 256); Uyat ölümdin qattiq. "Utanç ölümden daha acı." (KÖ 310); Uyqu dégen ölüm. "Uyku dediğin ölümdür." (KÖ 311); Yaxşi bolsañ toyuñğa bararmen, yaman bolsañ ölümiñge. "İyi olursan düğününe gelirim, kötü olursan ölümüne.” (LD 620); Yaman xotun erge ölüm. "Kötü kadın kocaya ölüm.” (KÖ 320); Zulum bar yerde ölüm bar. “Zulüm olan yerde ölüm var.” (LD 677) 


\section{Ölen Kişi İçin Kullanılan Sözcükler}

cansiz: Ölmüş, hayatını yitirmiş anlamında kullanılan bu sözcük, Uygur atasözlerinde çok az geçmektedir.

Canliq nadan ölük, cansiz alim tiriq. "Canlı cahil ölü, cansız âlim diridir.” (LD 135); Ölümge ă̆i yoq, cansizğa qara (yoq). "Ölüme çare yok, cansıza kara (yok)." (EİM 234)

méyit: Ölü (Necipoviç Necip 1995: 272) anlamında kullanılan bu sözcük, Uygur atasözlerinde çok az kullanılmıştır. Méyit sözcügünün geçtiği aşağıdaki atasözünde ölü ile şehit arasındaki ayrıma dikkat çekilmiştir.

Ceñde ölgen şéhit, cédelde ölgen méyit. "Savaşta ölen şehit, kavgada ölen ölü." (LD 139).

ölük: Ölü, ceset (Necipoviç Necip 1995: 305) anlamına gelen bu sözcük, Uygur atasözlerinde s1kça geçmektedir.

Béxilniñ ölükini it yémes, tirikini pit (yémes). "Cimrinin ölüsünü köpek yemez, dirisini bit (yemez)." (Eİ 282); Bir yolvasniñ ölügi miñ tülküni toydurar. "Bir kaplanın ölüsü bin tilkiyi doyurur." (KÖ 140); Canliq nadan ölük, cansiz alim tiriq. "Canlı cahil ölü, cansız âlim diridir.” (LD 135); Herkim öz ölügi üçün yiğlar. "Herkes kendi ölüsü için ağlar.” (MR 9); İmam öyidin aş, ölük közidin yaş. "İmam evinden aş, ölü gözünden yaş.” (KÖ 206); Ölük işt paltidin qorqmas. "Ölü köpek baltadan korkmaz. (Ölmüş eşek kurttan korkmaz.)" (LD 467); Ölük yolvastin tirik çaşqan yaman. "Ölü kaplandan canlı sıçan kötü.” (EI 54); Ölükke gör tépilğanda tirikke öy tépilar. "Ölüye mezar bulununca sağ olana da ev bulunur.” (KÖ 256); Ölükniñ közi yaman, uruşqanniñ sözi. “Ölünün gözü kötü, sahtekârın sözü." (KÖ 256); Qarğu müşükke ölük çaşkan uçraptu. "Kör kediye ölü sıçan rastlarmış." (KÖ 270); Rast sözdin ölük tirilidu. "Doğru sözle ölü bile dirilir.” (KÖ 284, 285); Tirik çaşqan ölük yolvastin küçlük. "Canlı sıçan ölü kaplandan güçlüdür." (KÖ 300, 301); Tirik dunyağa toymas, ölük duă̆a. "Canlı dünyaya doymaz, ölü duaya." (LD 576); Tirikke öy tépilar, ölükke gör. "Diriye ev bulunur, ölüye mezar." 
(KÖ 301); Yaxşi it ölügini körsetmes, yaxşi adem eyibini (körsetmes). "İyi it ölüsünü, iyi insan kusurunu göstermez.” (LD 622)

rehmetlik: Rahmetli (Necipoviç Necip 1995: 331) anlamında kullanılan bu sözcüğün Uygur atasözlerinde kullanım sıklığı fazla değildir.

Ölmigüçe rehmetlik bolmas. “Ölmedikçe rahmetli olmaz.” (LD 467)

şéyit/şéhit: Şehit anlamında kullanılan bu sözcük, kutsal bir amaç ya da inanç uğruna ölen kişiyi karşılamaktadır. Şehitlik farklı bir mertebedir. İslam inancına göre şehidin kabir azabı çekmeyeceği, kanının ilk damlası yere düştüğü anda kul hakları dışında bütün günahlarının affedileceği ve cennete ilk girenlerden olacağı ifade edilmiştir (Atar 2010: 429).

On ölüktin bir șéhit ela, on şéhittin bir tirik (ela). "On ölüden bir şehit âlâ, on şehitten bir diri âlâdır." (LD 453); Ceñde ölgen șéhit, cédelde ölgen méyit. "Savaşta ölen şehit, kavgada ölen ölü.” (LD 139); Miñ șéyittin bir tirik ela. "Bin şehitten bir diri yeğdir." (KÖ 244)

\section{Ölüm ile İlgili Eylemler}

baş kes-: Yeni Uygur Türkçesinde öldürmek, baş kesmek anlamlarını karşılamaktadır.

Bök al tise baș késiptu. "Börk al desen, baş keser." (KÖ 143); Égilgen bașni qiliç kesmes. "Eğilen başı kılıç kesmes." (LD 216)

can al-: Yeni Uygur Türkçesinde öldürmek, can almak anlamlarına gelir.

Ağriq örüse céniñni alur, sipa örüse puluñni alur. "Hastalık yıkarsa canını alır, memur yıkarsa malını alır." (KÖ 80)

can ber-: Ölmek, can vermek, kendini feda etmek anlamlarında kullanılır. 
Biri altun tavaqta nan yer, biri nan üçün can bérer. "Biri altın tabakta ekmek yer, biri ekmek için can verir." (LD 114); Can tumşuqqa kelgiçe can berme. "Can burnuna (ağza) gelmeyince can verme.” (LD 136)

can bilen çiq-: Ölünceye kadar devam etmek anlamına gelmektedir.

Qan bilen kirgen, can bilen çiqar. "Kanla giren, canla çıkar.” (KÖ 268); Süt bilen kirgen can bilen çiqidu. "Sütle giren canla çıkar." (KÖ 293, 294)

can çik-: Ölmek, canı çıkmak anlamlarında kullanılır.

Séxiniñ bergüsi kelse béxilniñ céni çiqiptu. "Cömert vermek isteyince, cimrinin canı çıkar." (KÖ 288); Can çiqmigiçe, ümüt ketmes. "Ç1kmayan candan ümit kesilmez." (KÖ 148); Can çiqqanda süre Yasin'niñ nimi işi bar? "Can çıktıktan sonra Yasin suresi ne işe yarar?" (KÖ 148); Ecel yetmey can çiqmas, béxil baydin nan çiqmas. "Ecel gelmeden can çıkmaz, cimri zenginden ekmek çıkmaz.” (LD 189)

candin keç-: Ölmek, candan geçmek anlamlarında kullanılır.

Béxil cénidin kéçer, mélidin keçmes. "Cimri canından geçer, malından geçmez." (Eİ 282); Can dostuñ cénidin kéçer, mal dostuñ mélidin keçmes. "Can dostun canından geçer, mal dostun malından geçmez.” (KÖ 148); Candin keçmigiçe, cananga yetmes. “Candan vazgeçmeyince, canana kavuşulmaz.” (KÖ 149)

candin ümüt üz-: Yeni Uygur Türkçesinde yaşamdan ümidi kesmek anlamında kullanılır.

Kim cénidin ümüt üzse köñlide bar sözni éytivalidu. "Kim canından ümidini kesse gönlünde olan sözü söyler.” (LD 324)

ecel kel-: Yeni Uygur Türkçesinde eceli gelmek anlamında kullanılmaktadır.

Ecel kelse eqil qaçar. "Ecel gelince akıl kaçar." (AE 40); Ecel kelgende macal kalmas. "Ecel geldiğinde mecal kalmaz." (EİM 221)

ecel yet-: Yeni Uygur Türkçesinde eceli gelmek anlamında kullanılır. 
Ecel yetmey can çiqmas, béxil baydin nan çiqmas. "Ecel gelmeden can çıkmaz, cimri zenginden ekmek çıkmaz.” (Eİ 281)

ecili püt-: Yeni Uygur Türkçesinde eceli gelmek anlamını karşılamaktadır.

Ecili pütken qarğa qarçuğa bilen oynaydu. "Eceli gelen karga şahinle oynar." (AE 41)

ecili tüg-: Yeni Uygur Türkçesinde eceli gelmek anlamında kullanılır.

Ecili tügken çaşqan möşük bilen oynaydu. "Eceli gelen sıçan kedi ile oynar." (LD 190)

haza tut-: Yas tutmak (Necipoviç Necip 1995: 151) anlamına gelen bu eylem, Uygur atasözlerinde ölünün ardından duyulan üzüntüyü belirtmek için kullanılır.

Çaşqan ölse müşük haza tutuptu. "Fare ölünce kedi yas tutar.” (LD 148); Düşminiñ ölse haza tutma, vapasizdin dost tutma. "Düşmanın ölünce yas tutma, vefasızdan dost tutma." (LD 188)

öl-: Hayatın sona ermesi anlamında kullanılan bu eylem, Uygur atasözlerinde aynı anlamı karşılayan diğer eylemlere oranla çok daha fazla kullanılmıştır.

Açliqqa hiç kişi ölmes. "Açliktan hiç kimse ölmez." (KÖ 72); Açliqtin ölseñmu, ata-anañni taşlima. "Açlıktan ölsen de ananı babanı atma." (LD 29); Adem ölidu, dunya qalidu. "İnsan ölür, dünya kalır." (Eİ 86); Alma yep ăgriq bolğiçe örük yep öl. "Elma yiyip hasta olacağına, kayısı yiyip öl." (KÖ 86); Asman yiraq, yer kattiq, öley disem can tatliq. "Gök uzak, yer sert, öleyim desem can tatl1." (KÖ 93); At ölse égiri qalar, adem ölse éti. "At ölse eyeri kalır, insan ölse adı. (At ölür, meydan kalır; insan ölür, şan kalır.)" (LD 68); At ölse itniñ toyi bolidu. “At ölse köpeğin düğünü olur.” (AE 4); Atañ ölse ölsün, atañni körgenler ölmisun. "Baban ölürse ölsün, babanı görenler ölmesin." (EIM 263); Balañ ölse erge baq, ériñ ölse yerge (baq). “Çocuğun ölürse kocana bak, kocan ölürse yere (bak)." (MR 177); Berseñ yeymen, ursañ ölimen. "Verirsen yerim, vurursan ölürüm.” (AE 64); Étiñ öldi-atañ öldi. “Atın öldü, baban öldü.” (MR 212) 


\section{Ölüm Zamanı ile İlgili Sözcükler}

biecel/béecel: Eceli gelmeden anlamını karşılamaktadır.

Atañ atğan dukanda paxta at, biecel öley déseñ, tam tüvige bérip yat. "Babanın attığı dükkânda pamuk at, ecelsiz öleyim dersen, gidip duvar dibine yat.” (KÖ 104); Qiriq yil qirğin bolsa béecel çivin ölmes. "Kırk y1l kıran olsa ecelsiz sinek ölmez." (KÖ 277)

ecel: Hayatın sonu, ölüm zamanı anlamında kullanılır. Allah tarafından her canlı için önceden takdir edilen hayat süresini ve bu sürenin sonu olan ölüm vaktini ifade etmek için kullanılır (Tunç 1994: 380).

Qorqqanni ecel qoğlar. "Korkanı ecel kovalar." (KÖ 281); Derd köpeyse elem bolur, elem köpeyse ecel (bolur). "Dert çoğalsa elem olur, elem çoğalsa ecel (olur)." (LD 168); Ecel yoli keklikniñ qedimidinmu qisqa. "Ecel yolu kekliğin ayağından da k1sa." (LD 189); Eceldin burun dora qil, oçaqqa qarap mora qil. "Ecelden önce çare bul, ocağa göre baca yap.” (LD 189)

ecelsiz: Eceli gelmeden anlamında kullanılan bir sözcüktür.

Ecelsiz béliq quruqluqtimu ölmes. "Eceli gelmeyen balık karada da ölmez." (LD 190)

Ezrail: Dört büyük melekten ölüm zamanı geldiğinde can almakla görevli olandır (K1lavuz 1991: 350).

Ezrail'din cinmu qéçip qutulalmas. “Azrail'den cin de kaçamaz.” (LD 215); Şeyx nan sorar, Ezrail can (sorar). "Şeyh ekmek sorar, Azrail can (sorar).” (LD 552)

\section{Ölünün Gömülmesi ile İlgili Sözcükler}

cinaze: Türkiye Türkçesinde ölü, kefenlenmiş gömülmeye hazır ölen kişi anlamına gelen cenaze sözcügü (Türkçe Sözlük: 357), Yeni Uygur Türkçesinde ölü anlamının yanında tabut anlamını da karşılamaktadır. Uygur atasözlerinde cinaze 
sözcügünün geçtiği bir örneğe rastlanmış ve bu örnekte sözcük tabut anlamında kullanılmıştır.

Ölgenge cinaza kérek, tuğulğanğa böşük. "Ölene tabut gerek, doğana beşik.” (LD 465)

gör: Bu sözcük Yeni Uygur Türkçesinde kabir, mezar (Necipoviç Necip 1995: 134) anlamında kullanılmaktadır. Kabirler, toplumlarda simgesel açıdan önemli bir fonksiyon üstlenmiş ve bir yandan öteki dünyaya açılan kapılar, diğer yandan ölümü hatırlatan abideler hüviyetine bürünmüştür (Demirci 2001: 33).

Dok görge kirgende tüziler. "Kambur mezara girince düzelir." (AE 180); Er qérisa qiz alur, xotun qérisa gör alur. "Erkek yaşlansa kız alır, kadın yaşlansa mezar alır." (KÖ 173); Görge kirgen tirik çiqmas, öyge kirgen quruq (çiqmas). "Mezara giren diri çıkmaz, eve giren boş (çıkmaz).” (AE 295); İçi tarniñ göri tar. "Kıskancın mezarı da dar olur." (KÖ 204); Ölükke gör tepilğanda tirikke öy tépilar. "Ölüye mezar bulununca sağ olana da ev bulunur." (KÖ 256); Tirikke öy tépilar, ölükke gör. "Diriye ev bulunur, ölüye mezar.” (KÖ 301); Toymas közni görniñ topisi toydurar. “Açgözlüyü mezar topră̆ 1 doyurur." (KÖ 304); Yamanğa gördimu xoşna bolma. "Kötüye mezarda bile komşu olma." (KÖ 321); Namerdke qerzdar bolma, hem yolda qistar hem görde. "Namerde borçlu olma, hem yolda hem mezarda sıkıştırır." (LD 438)

göristan: Yeni Uygur Türkçesinde mezarlık anlamına gelmektedir. Mezarlıkların oluşması defin geleneği ile ilgilidir. Mezar, daha çok toprak üstünde kalan yapısı ile önem taşır ve ziyaret edilebilmesi için üzerinde ait olduğu kişiyi belirleyen bir işaretin bulunması gerekir. Geleneğin ne zaman başladığı ile ilgili kesin bir bilgi bulunmamaktadır (Bozkurt 2004: 519).

Baliliq öy-gülistan, balisiz öy-göristan. "Çocuklu ev gülistan, çocuksuz ev kabristan." (EIM 119); Yaxşi xotun öyniñ gülistani, yaman xotun öyniñ göristani. "İyi hanım evin gülistanı, kötü hanım evin kabristanıdır.” (LD 622)

képen: Kefen (Necipoviç Necip 1995: 198) anlamında kullanılan bu sözcük, cenazenin yıkanıp kurulandıktan sonra gömülmek üzere sarıldığg bezi karşılamaktadır. 
Ölen kimsenin yıkanıp genelde beyaz olan temiz bir beze sarılarak gömülmesi hemen hemen bütün medeniyet ve dinlerde cenaze kültünün önemli bir ögesini teşkil eder (Keskin 2002: 184).

A grriştin ilgiri képiniñni teyyarla. "Hasta olmadan önce kefenini hazırla." (KÖ 79); Képil bolsañ, képiniñ köyer. "Kefil olsan, kefenin yanar." (KÖ 219); Öley disem képen yoq. "Öleyim desem kefen yok." (KÖ 255); Toymas képinini sétip yeptu. “Açgözlü, kefenini satıp yemiş." (LD 582); Yağçi hidsiz kişi, bözçi képensiz. "Yağc1 kokusuz kişi, kumaşçı kefensiz kişi.” (LD 618); Cuvazçi yağsiz kéter, xalvap képensiz. "Yağcı yağsız gider, kilimci kefensiz gider." (LD 142)

qebir: Bu sözcük Yeni Uygur Türkçesinde kabir, mezar anlamına gelir. Kabir sözcüğü, İslam inancına göre sadece ölünün yattığı yeri değil, ölüm ile mahşerdeki diriliş arasında insanların yaşayacağı berzah hayatını da ifade eder (Toprak 2001: 37).

Açqa ölgenniñ qebrisi yoq. "Açlıktan ölenin kabri yok." (Eİ 278)

mazar: Bu sözcük Yeni Uygur Türkçesinde kabir, mezar anlamında kullanılmaktadır. Ölümden sonra bedenler coğrafyaya ve zamana göre değişik şekillerde defnedilmiştir. Tarih öncesi toplulukların ve günümüzde mevcut bazı ilkel kültürlerin ölü gömme adetleri aynı değildir. Her şeye rağmen yaygın uygulama, cesetleri toprağa çukur açılarak oluşturulan mezarlara gömme şeklinde olmuştur (Demirci 2001: 33, 34). Uygurlarda İslamiyet'in etkisiyle ölü gömme adetlerinde birtakım değişikler yaşanmış ancak yeni adetler eski adetlerin tamamen ortadan kalkmasına neden olmamıştır (Rahman 1996: 113).

Baliliq öy bazar, balisiz öy mazar. "Çocuklu ev pazar, çocuksuz ev mezar." (AE 61); Divaneniñ mazar bilen héç bir gahta işi yoq, töginiñ bazar bilen héç bir gahta işi yoq. "Divanenin hiçbir zaman mezarla işi yok, devenin hiçbir zaman pazarla işi yok." (KÖ 160); Kacni bazar oñlaydu, sarañni mazar. "Tembeli pazar düzeltir, aptalı mezar." (KÖ 215); Mazar körgen mollidin qorq. "Mezar gören molladan kork." (LD 414); Molla bolsañ mazarda bol, sodiger bolsañ bazarda (bol). "Molla isen mezarda, tüccar isen pazarda ol." (LD 427); Puli barğa bazar, puli yoqqa mazar. "Parası olana pazar, 
parası olmayana mezar." (LD 502); Şeyx mazardin qalmas, sodiger bazardin qalmas. “Şeyh mezardan, tüccar pazardan kalmaz.” (LD 551); Teretsiz mazarğa barmañ, pulsiz bazarğa. “Abdestsiz mezara, parasız pazara gitmeyin.” (LD 568)

\section{Ölüm Sonrası Hayat ile İlgili Sözcükler}

axiret: Dünya hayatından sonra başlayıp ebediyen devam edecek olan ikinci hayat anlamında kullanılmaktadır Ahiret inancı, ilkel kavimler dâhil, Tanrı'nın varlığını kabul eden hemen hemen bütün din ve düşünce sistemlerinde mevcuttur (Topaloğlu 1988: 543).

Dunya işini axiretke qaldurma. "Dünya işini ahirete birakma." (LD 185); Vapadar dost axiretkiçe. "Vefalı dost ahirete kadar." (LD 612)

behiş/bihiş: Cennet anlamına gelen bu sözcük, müminlerin ölümden ya da kıyametin kopmasından sonra sonsuz mutluluk içinde yaşayacakları yeri karşılamaktadır (Şahin 1992: 374).

Dozaqqa ögengen könül bihișke könelmeptu. "Cehennemi öğrenen gönül cennete alışamamış." (LD 184); Dozaqqa ögengen bihișqa tözmes. "Cehennemi öğrenen cennete dayanamaz.” (KÖ 163); Yaxşi xotun behis.. "İyi kadın cennettir.” (KÖ 314)

dozaq/dozax: Cehennem anlamına gelen bu sözcük, inkârcıların ve günahkârların ahirette cezalandırılacakları yeri karşılamaktadır (Harman 1993: 225).

Dozaqqa ketse yüzi qizarmeydu. "Cehenneme girse yüzü kızarmaz.” (KÖ 163); Yaxşi kün cennet, yaman kün dozax. "İyi gün cennet, kötü gün cehennem.” (LD 623); Cennetke kösey taqaşmas, dozaxqa selle (yaraşmas). "Cennete ateş kancası yakışmaz, cehenneme sarık (yakışmaz)." (EIMM 237); Dost ayriğan dozax tüvide. "Dost ayıran cehennem dibinde." (AE 176)

cehennem: İnkârcıların ve günahkârların ahirette cezalandırılacakları yer anlamına gelmektedir. Ölümden sonraki hayat ile ilgili inançlar hemen hemen bütün dinlerde vardır ve kötü davranışların cezalandırılacağına inanılır (Harman 1993: 225). 
Zalimniñ cayi cehennem. "Zalimin yeri cehennem.” (LD 673); Pixsiqniñ öyi cehennem. "Pintinin evi cehennem." (LD 496)

cennet: Dinî inanışlara göre müminlerin ölümden ya da kıyametin kopmasından sonra sonsuz mutluluk içinde yaşayacakları yer anlamına gelmektedir (Şahin 1992: 374). Ebedî saadet yurdunu ifade etmek üzere Kur'an-1 Kerim'de, muhtelif hadislerde ve diğer İslami eserlerde yer alan isimler içinde en çok kullanılan, içindeki bütün mekân ve imkânları kapsayacak şekilde muhtevası geniş olan bir sözcüktür (Topaloğlu 1993: 376). Dinler tarihine dair araştırmalar, hemen hemen her din ve inanç sisteminde ölüm sonrası hesaplaşmanın, mükâfat ya da cezanın varlığının kabul edildiğini göstermiştir (Topaloğlu 1993: 378).

Ana ayiğida cennet bar. "Ana ayağında cennet var." (KÖ 98); Yaxşi xotun cennetniñ gülidur, yaman xotun dozaxniñ külidur. "İyi hatun cennetin gülüdür, kötü hatun cehennemin külüdür.” (LD 621); Hesetxurniñ közi cennet, köñli dozax. “K1skancin gözü cennet, gönlü cehennem.” (LD 264); Hurunğa cennetmu dozax. “Tembele cennet de cehennem.” (LD 272)

qiyamet: Kıyamet anlamındaki bu sözcük, dünyanın bağlı olduğu kozmik sistemde meydana gelecek değişimi ifade eder. Dinî inanışlara göre bu değişimin ardından ölülerin diriltilmesi ile ebediyen devam edecek olan bir âlem başlayacaktır (Topaloğlu 2002: 516, 517).

Qiyamet kelse qoşnidin. "Kıyamet gelse komşudan.” (EIMM 243); Qérindaş ölümi qiyamet. "Kardeşin ölümü kıyamet." (LD 381)

\section{Sonuç}

Uygur atasözlerinde öl- için can ber- sözcüğünün kullanılması yoluyla üzüntü uyandıran bir sözcüğün yumuşatılarak ifade edilmesini örnekleyen, toplumun üzücü sözcükleri örtülü biçimde söyleme amacına yönelen yapılar görülmektedir. 
Ölüm ile ilgili Uygur atasözlerinde Türkiye Türkçesindeki ile benzer atasözleri yer almaktadır: YUT Elçige ölüm yoq. "Elçiye ölüm yok.”, TT Elçiye zeval olmaz.; YUT At ölse égiri qalar, adem ölse éti. “At ölse eyeri kalır, insan ölse adı.”, TT At ölür, meydan kalır; insan ölür, şan kalır. Bu benzerlikleri, Türk boylarının ortak düşünce ve tutumunun bir göstergesi olarak yorumlamak mümkündür.

Hayatın son durağı olan ölüm, Uygur atasözlerinde kendine yer bulmuş ve ölüm ile ilgili pek çok sözcük kullanılmıştır. Bu sözcükleri ölen kişi için kullanılan sözcükler, ölüm ile ilgili eylemler, ölüm zamanı ile ilgili sözcükler, ölünün gömülmesi ile ilgili sözcükler ve ölüm sonrası hayat ile ilgili sözcükler şeklinde sınıflandırmak mümkündür. Uygur atasözlerinde ölen kişi için cansiz, méyit, ölük, rehmetlik, şéyit/şéhit sözcükleri kullanılırken, ölünün gömülmesi ile ilgili olarak cinaze, gör, göristan, képen, qebir, mazar sözcükleri kullanılmaktadır. Ölüm ile ilgili olarak baş kes-, can al-, can ber-, can bilen çiq-, can çik-, candin keç-, candin ümüt üz-, ecel kel-, ecel yet-, ecili püt-, ecili tüg-, haza tut-, öl- eylemleri atasözlerinde yer edinmiş, biecel/béecel, ecel, ecelsiz, Ezrail sözcükleri ise hayatın sonu, ölüm zamanı ile ilgili olarak kullanılmıştır. Axiret, behiş/bihiş, dozaq/dozax, cehennem, cennet ve qiyamet sözcükleri ise ölüm sonrası hayat ile ilgili sözcüklerdir. Uygur atasözlerindeki ölüm ile ilgili bu sözcükler, Uygurların ölüm ile ilgili dünya görüşünü yansıtmakta, ölüm ile ilgili sözcük yelpazesinin bu kadar geniş olması onların gözlemlerinde ölümün ne kadar yer edindiğini göstermektedir. 


\section{KAYNAKÇA}

AKSAN, Doğan (1995). Her Yönüyle Dil Ana Çizgileriyle Dilbilim, Ankara: Türk Dil Kurumu Yayınları.

AKSAN, Doğan (2004). Türkçenin Sözvarlı̆̆l, Ankara: Engin Yayınevi.

AKSOY, Ömer Asım (1988). “Atasözleri, Deyimler”, Tük Dili Araştırmaları Yıllı̆̆ Belleten 1962, ss. 131-166.

AKSOY, Ömer Asım (1993). Atasözleri ve Deyimler I Atasözleri Sözlüğü, İstanbul: İnkılâp Yayınları.

ALKAYA, Ercan (2001). "Tatar Türkçesindeki Dil ve Söz ile İlgili Atasözleri Üzerine Bir Değerlendirme”, Firat Üniversitesi Sosyal Bilimler Dergisi, 11(2): 55-76.

ALTAYLI, Seyfettin (2010). “Atasözü ve Deyimler Arasındaki Farklar”, Karadeniz Araştırmalarl, 25: 125-134.

ATAR, Fahrettin (2010). "Şehid", İslâm Ansiklopedisi, Cilt 38, ss. 428-431, İstanbul: Türkiye Diyanet Vakfı Yayınları.

BENVENISTE, Emile (1995). Genel Dilbilim Sorunlarl, çev. Erdim Öztokat, İstanbul: Yapı Kredi Yayınları.

BİRAY, Nergis (2013). "Kazak Türklerinde Ölümle İlgili Kelime, Kelime Grubu ve Deyimlerden Hareketle Ölüm Kavramı", Prof. Dr. Abdurrahman Güzel Armăganı, ed. Doç. Dr. C. Demir, Yrd. Doç. Dr. H. Parlakyıldız, ss. 353-371, Ankara: Akçağ Yayınları.

BOZKURT, Nebi (2004). "Mezarl1k”, İslâm Ansiklopedisi, Cilt 29, ss. 519-522, İstanbul: Türkiye Diyanet Vakfı Yayınları.

CHOMSKY, Noam (2001). Dil ve Zihin, Ankara: Ayraç Yayınları.

ÇOBANOĞLU, Özkul (2004). Türk Dünyası Ortak Atasözleri Sözlüğü, Ankara: Atatürk Kültür Merkezi Yayınları.

ÇOTUKSÖKEN, Yusuf (2004). Türkçe Atasözleri ve Deyimler Sözlüğü, İstanbul: Toroslu Kitaplığı.

DEMİRCİ, Kürşat (1993). “Cenaze”, İslâm Ansiklopedisi, Cilt 7, ss. 353-354, İstanbul: Türkiye Diyanet Vakfı Yayınları.

DEMİRCI, Kürşat (2001). "Kabir”, İslâm Ansiklopedisi, Cilt 24, ss. 33-35, İstanbul: Türkiye Diyanet Vakfı Yayınları.

DİLÇìN, Cem (1983). Türkiye Türkçesinin Sözvarlı̆̆ı ve Tarihsel Sözlüğü, Ankara: Türk Tarih Kurumu.

DOĞAN, Levent (2009). "Uygur Atasözlerinde Yüceltilen Değerler”, Trakya Üniversitesi Sosyal Bilimler Dergisi, 11(1): 87-104. 
DUMAN, Mustafa (2012). “Türk Atasözlerinde Ölüm”, Prof. Dr. Fikret Türkmen Armă̆anı, ed. Alimcan İnayet ve Zeki Kaymaz, ss. 97-108, İzmir: Ege Üniversitesi Basımevi.

EMET, Abliz (2001). Uyğur Xelq Maqal-Temsilliri İzahliq Luğiti, Kaşgar: Kaşgar Uygur Neşriyatı.

ERGAT, Emir Ali (2008). Felsefede Dil, Düşünce ve Varlık Illişkisi-J. Locke ve G. Berkeley Örneği $i$. İstanbul: Birey Yayınc1lık.

ERGUN, Pervin (2013). “Türk Kültüründe Ölümle İlgili Bazı Terimler”, Millî Folklor, 100: 134-148.

ERSOY, Ruhi (2014). “Türklerde Ölüm ve Ölü ile İlgili Rit ve Ritüeller”, Millî Folklor, 54: 86-101.

GÜNER DİLEK, Figen (2007). "Altay Türkçesinde Ölüm Kavramını Anlatan Sözler ve Söz Kalıpları”, Bilig, 42: 177-190.

HARMAN, Ömer Faruk (1993). "Cehennem”, İslâm Ansiklopedisi, Cilt 7, ss. 225-226, İstanbul: Türkiye Diyanet Vakfı Yayınları.

İBRAHIM, Sıdıqcan (2004). "Uyğur Xelq Maqal-Temsilliride Eks Etken Ayallar Heqqidiki Qaraşlar”, Şincañ Pédagogika Univérsitéti İlmiy Jurnili, 1: 35-37.

KARAMAN, Ahmet (2016). "Uygur Atasözlerinde Kadın”, Türk Dünyası Dil ve Edebiyat Dergisi, 41: 93-111, Ankara: Türk Dil Kurumu Yayınları.

KESKIN, Mehmet (2002). “Kefen”, İslâm Ansiklopedisi, Cilt 25, ss. 184-185, İstanbul: Türkiye Diyanet Vakfı Yayınları.

KILAVUZ, Ahmet Saim (1991). "Azrâil”, İslâm Ansiklopedisi, Cilt 4, ss. 350351, İstanbul: Türkiye Diyanet Vakfı Yayınları.

MEHMUT, Ababekri (2006). "Uyğur Xelq Maqal-Temsilliridiki Balilar Terbiyisi Toğrisida", Xoten Pédagogika Aliy Téxnikomi İlmiy Jurnili, 3: 49-51.

NECIPOVİÇ NECİP, Emir (1995). Yeni Uygur Türkçesi Sözlüğü, çev. İklil Kurban, Ankara: TDK Yayınları.

ÖGER, Adem (2013). Uygur Türklerinde Törenler ve Bayramlar, Ankara: Grafiker Yayınları.

ÖGER, Adem ve Alimcan İNAYET (2013). "Uygur Türklerinde Ölüm ile İlgili İnanış ve Adetler”, Uluslararası Uygur Araştırmaları Dergisi, 1(2): 49-64.

ÖZKIRIMLI, Atilla (1994). Dil ve Anlatım, Ankara: Ümit Yayınc1lık.

ÖZTOPÇU, Kurtuluş (1992). Uygur Atasözleri ve Deyimleri, İstanbul: Doğu Türkistan Vakfı Yayınları.

QURBAN, Abla (2008). "Uyğur Xelq Maqal-Temsilliridiki İctimaiy Exlaq Köz Qaraşliri Heqqide Qisqiçe Mulahize", Qeşqer Pédagogika Institüti İlmiy Jurnili, 2: 4953. 
RAHMAN, Abdukerim (1996). Uygur Folkloru, çev. Soner Yalçın ve Erkin Emet, Ankara: Kültür Bakanlığı Yayınları.

REHİM, Mehemmet (1979). Uy ğur Xelq Maqal-Temsilliri, Ürümçi: Şincan Halk Neşriyatı.

SADIK, Mehemmetcan (1995). Uyğur Xelq Éğiz Edebiyati Heqqide. Ürümçi: Şincan Halk Neşriyatı.

SAĞLAM, Musa Yaşar (2001). “Atasözleri ve Deyimlerde İmgelem”, Hacettepe Üniversitesi Edebiyat Fakültesi Dergisi, 18(I): 45-51.

SEPER, Sulayman ve Nesirulla YOLBOLDİ (2002). Hazirqi Zaman Uyğur Tili (Tüzitilgen Nusqisi), Ürümçi: Şincan Halk Neşriyatı.

ŞAHIN, M. Süreyya (1992). “Cennet”, İslâm Ansiklopedisi, Cilt 7, ss. 374-376, İstanbul: Türkiye Diyanet Vakfı Yayınları.

TOPALOĞLU, Bekir (1988). “Âhiret”, İslâm Ansiklopedisi, Cilt 1, ss. 543-548, İstanbul: Türkiye Diyanet Vakfı Yayınları.

TOPALOĞLU, Bekir (1993). “Cennet”, İslâm Ansiklopedisi, Cilt 7, ss. 376-386, İstanbul: Türkiye Diyanet Vakfı Yayınları.

TOPALOĞLU, Bekir (2002). "Kiyamet”, İslâm Ansiklopedisi, Cilt 25, ss. 516522, İstanbul: Türkiye Diyanet Vakfı Yayınları.

TOPRAK, Süleyman (2001). "Kabir”, İslâm Ansiklopedisi, Cilt 24, ss. 37-38, İstanbul: Türkiye Diyanet Vakfı Yayınları.

TOSUN, İlker (2017). “Tuvacada Ölümle İlgili Örtmeceler”, Tuva Araştırmaları Tuvaca Varyantların Belgelenmesi ve Tanımlanmasi, ss. 165-184, Ankara: Grafiker Yayınları.

TUNÇ, Cihat (1994). "Ecel”, İslâm Ansiklopedisi, Cilt 10, ss. 380-382, İstanbul: Türkiye Diyanet Vakfi Yayınları.

Türk Dil Kurumu (2005). Türkçe Sözlük, Ankara: TDK Yayınları.

WEIN, Hermann (1959). Tarih, Insan ve Dil Felsefesi Üzerine Alt Konferans, çev. İsmail Tunalı, İstanbul: İstanbul Üniversitesi Edebiyat Fakültesi Yayınları.

YAKUB, Abliz ve Ğenizat ĞEYURANİ (1999). Uyğur Tiliniñ İzahliq Luğiti, Ürümçi: Şincan Halk Neşriyatı. 


\section{KISALTMALAR VE TARANAN ESER KISALTMALARI}

AE EMET, Abliz (2001). Uyğur Xelq Maqal-Temsilliri İzahliq Luğiti, Kaşgar: Kaşgar Uygur Neşriyatı.

Eİ İMİN, Exmet (2006). Uyğur Xelq Maqal-Temsilliri 1, Ürümçi: Şincan Halk Neşriyat1.

EIM İMIN, Exmet (2006). Uyğur Xelq Maqal-Temsilliri 2, Ürümçi: Şincan Halk Neşriyatı.

HEH SADIK, Mehemmetcan (1995). Uyğur Xelq Éğiz Edebiyati Heqqide. Ürümçi: Şincan Halk Neşriyatı.

KÖ ÖZTOPÇU, Kurtuluş (1992). Uygur Atasözleri ve Deyimleri, İstanbul: Doğu Türkistan Vakfı Yayınları.

LD DOĞAN, Levent (2011). Uygur Atasözleri-Uyğur Maqalliri, İstanbul: Sembol Grup Baskı Yayın.

MR REHİM, Mehemmet (1979). Uyğur Xelq Maqal-Temsilliri, Ürümçi: Şincan Halk Neşriyatı.

TT Türkiye Türkçesi.

YUT Yeni Uygur Türkçesi. 